\title{
A novel metal-cutting technology for high-risk environments using self-excited oscillation pulsed abrasive water jet
}

\author{
Fei Xue ${ }^{1, a}$ \\ ${ }^{1}$ College of Resources \& Safety Engineering, China University of Mining \& Technology (Beijing), \\ Beijing 100083, China
}

a594762090@qq.com

Keywords: self-excited oscillation; pulsed water jet; cutting; high-risk environment

Abstract. The self-excited oscillation pulsed water jet is an efficient and valuable technology for cutting, especially for risky environments. In this paper, the pulsed water jet is explored to be used in high-risk environment for metal cutting. The abrasives are proposed to be added in to enhance its cutting ability. A portable cutting system is assembled and examined. The result shows that the cutting system is convenient and effective for risky environments.

\section{Introduction}

The self-excited oscillation pulsed water jet, which is a kind of discontinuous jet and produces pulsed impacts, is developed based on fluid dynamics, hydraulics, resonance and elastic theory of fluid. It is commonly agreed that the selective amplification and feedback of disturbance are the core elements to produce the pulsed jet ${ }^{[1-4]}$, as is shown in Fig. 1.

In Fig. 1(a), after water flow gets through the upstream nozzle, the high velocity and instable shear layer is disturbed by surrounding environment. The cross section of the jet, therefore, begins to expand and surpass the area of downstream nozzle. When the jet reaches downstream nozzle, it collides with downstream wall dramatically because of high kinetic energy. Since the collision lasts very short time, the majority of kinetic energy has been pushed back as reflected wave, which is called feedback in Fig. 1(b). The reflected wave has a strong ability to weaken the upcoming water flow, so the water jet during feedback process is weak. When the reflected wave arrives at upstream wall, the similar collision would happen again. At this time, the pressured wave is acting to accelerate the water flow substantially. The water jet within this time would have a strong power. The process runs over and over in Helmholtz cavity, and produces periodic pulsed jet.

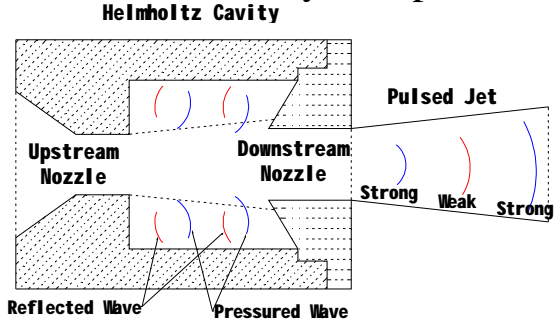

(a)

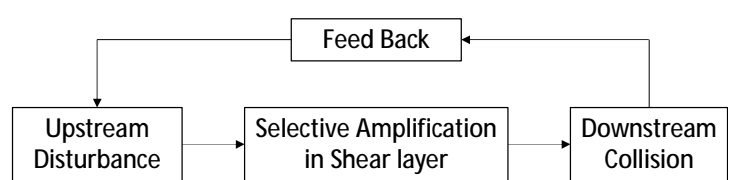

(b)

Fig. 1 Mechanism of Helmholtz cavity

In this paper, the pulsed water jet is explored to be used in high-risk environment for metal cutting. The abrasives are proposed to be added in to enhance its cutting ability. A portable cutting system is assembled and examined.

\section{Equipment design}

The pulsed water jet itself, even though its impact force is very high, has insufficient capacity to break metal materials. To enhance its cutting capacity, the abrasives shall be added in, as is shown in Fig. 2 . The abrasives mainly rely on cutting and deformation abrasion effect, brittle cracking and plastic flow effect to break materials ${ }^{[5-8]}$. Based on excellent pressure-boost ability of pulsed jet, the abrasives are 
able to obtain a very high kinetic energy. Obviously, the pulsed jet functions as an accelerator and the abrasives burden the cutting mission.

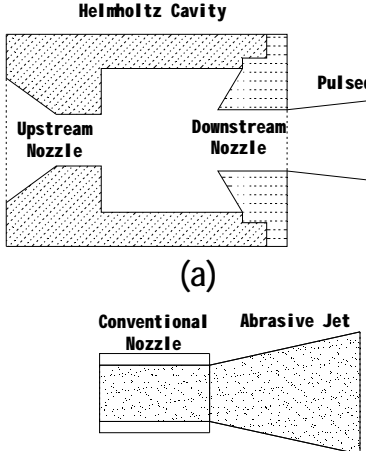

(b)

Fig. 2 Schematic diagram of pulsed abrasive water jet

In most cases, the pressure of water source is low and could not meet the pressure demand for cutting work. Therefore, a pressure-boost device is always needed. The whole system shall be portable and driven mechanically, as is shown in Fig. 3. The most important devices are pressure-boost pump, abrasive tank and pulsating nozzle. During cutting process, the water source provides low-pressure water flow for pump as driving medium. Then the pressure-boost pump would increase the velocity of water flow coming from another water source substantially. After that, the high-pressure water flow passes through the abrasive tank and mixes with abrasives. At last, the pressured abrasive water flow gets to the pulsating nozzle and becomes pulsed abrasive water jet.

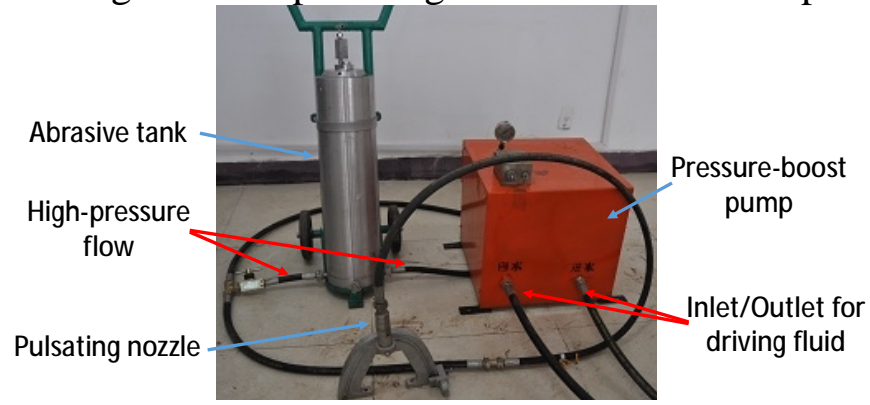

(1) Pressure-boost pump

Fig. 3 Portable cutting system

As the flow pressure of water source is always lower than needed pressure due to different reasons, a pressure-boost pump is necessary to raise the flow pressure a second time. Considering the target environment, the pressure-boost pump shall not be driven by electricity, but driven mechanically. Driven by flow means there is no need to consider anti-explosion enclosure and electricity demand, and that would substantially decrease its weight and extend its usage.

In Fig. 4(a), it shows the mechanical structure of selected pressure-boost pump. The pump is only $8 \mathrm{~kg}$ and available to use both water and emulsion as driving flow. The maximum output pressure is $40 \mathrm{MPa}$ and flow rate is $12 \mathrm{~L} / \mathrm{min}$, which is enough for pulsed abrasive water jet. In order to protect this pump from being broken by outside complex environment, an iron cover is added. A woolen board is also added to protect the pump and reduce its noise. The final weight is less than $15 \mathrm{~kg}$. The structure of this part is shown in Fig. 4(b).

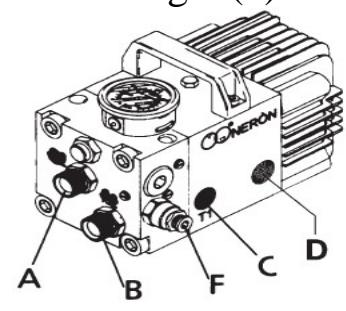

(a)

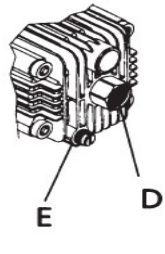

Fig. 4 Pressure-boost pump. A-low pressure water inlet; B-high pressure water outlet; C-driving flow inlet; D-driving flow

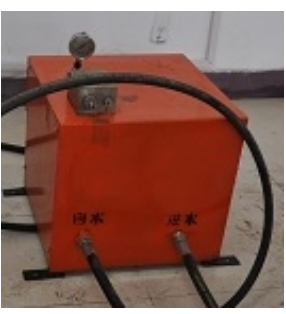

(b) outlet; E-safety valve; F-pressure limiting valve. 
(2) Abrasive tank

The abrasive tank is responsible for blending abrasives with water evenly. If the blend is insufficient, the impact force of jet would be substantially reduced.

As the tank needs to be conveniently moved, the volume is designed only $8 \mathrm{~L}$. The length and diameter of inner cavity is $500 \mathrm{~mm}$ and $140 \mathrm{~mm}$, respectively. Considering the pressure-withstanding and rust-proof requirements, the tank is made of martensitic stainless steel and able to stand $40 \mathrm{MPa}$ flow pressure.

The tank is comprised of three parts as is shown in Fig. 5. At the upper part are an end cap and an inlet for abrasives. On the end cap is an atmospheric exhaust valve from which the air could be driven out at beginning stage. The middle part is the blending cavity where the high-pressure flow and abrasives are mixed evenly. Designed at the lower part are inlet and outlet passages. The inlet passage is especially designed so that the inlet flow could blend abrasives more effectively.

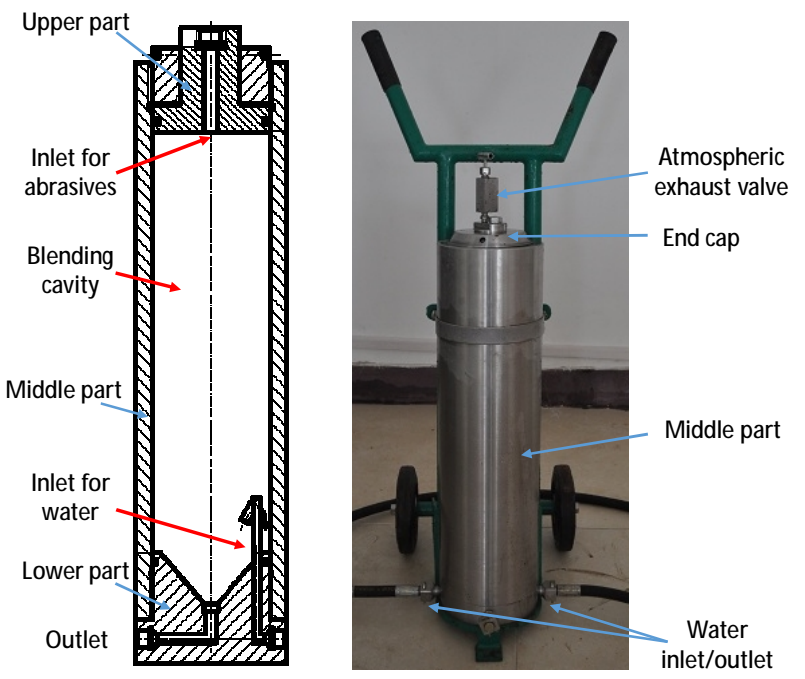

Fig. 5 Abrasive tank

(3) Pulsating nozzle

Considering the upstream and downstream nozzles need periodic replacement, the structure is assembled by three parts as is shown in Fig. 6. As long as the upper part or lower part is removed through thread structure, the upstream or downstream nozzle is exposed. In order to stand high pressure, double-deck seal rings are adopted so that the structure would not leak water under 80MPa. The material of the whole structure is stainless steel to avoid rust. Since the nozzles are the most abraded part, the nozzles are made of hard alloy.

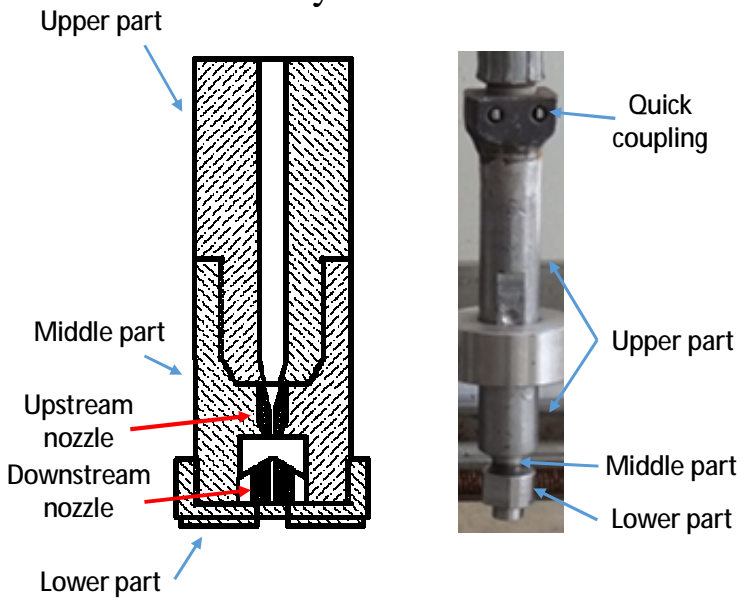

Fig. 6 Self-excited oscillation nozzle

\section{Verification}

To verify the effectiveness of the pulsed abrasive cutting system, a cutting trial is carried out. The cutting targets are two No.45 steel blocks, as is shown in Fig. 7(a). The size is $150 \mathrm{~mm} * 80 \mathrm{~mm} * 30 \mathrm{~mm}$. 
The block is fixed on the table by screws during cutting process, as is shown in Fig. 7(b). The nozzle is able to move along the axis. The target distance is $5 \mathrm{~mm}$. The selected abrasives are 80 -mesh garnets. The flow pressure is $25 \mathrm{MPa}$. The abrasive concentration is $6.3 \%$, which is obtained by recycling and testing the abrasive water flow.

The cutting result is shown in Fig. 7(c). It is obvious that the steel block could be cut off totally by the system. The time used for upper $10 \mathrm{~mm}$ is within $2 \mathrm{~min}$, for middle $10 \mathrm{~mm}$ is about $3.5 \mathrm{~min}$, and for bottom part is about 10min. There is no spark during the whole process. Therefore, the pulsed abrasive jet system is effective, safe and worth promoting.

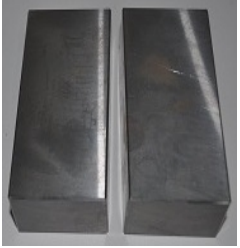

(a) steel block

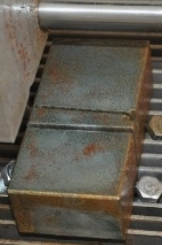

(b) fixed block

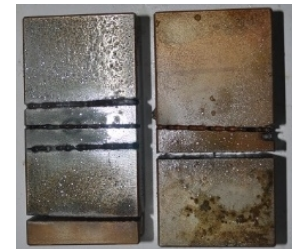

(c) cutting result

Fig. 7 cutting experiment of pulsed abrasive jet

\section{Conclusions}

The pulsed water jet is a type of valuable and effective cutting method. Relying on Helmholtz cavity, it owns a powerful pressure-boost ability. The feature is able to increase its impact force and accelerate the abrasives substantially. The abrasives have abrasion effect to deal with metals, which is not possessed by pure water.

Aiming at high risk environments, two factors are taken into consideration: the first is anti-explosion, the other one is convenience. In this portable cutting system, a mechanically driven pump is selected for pressure-boost use. The pump is driven by fluid and available in any situation. In addition, abrasive tank and pulsating nozzle are both specially designed to meet the requirements. When used in explosion-prone environment, the mechanically driven pump is able to provide high-pressure flow. The system could work immediately and finish the cutting mission safely and quickly, which makes it more valuable in high-risk environments.

\section{References}

[1] P. Wang, H.J. Ni, R.H. Wang, et al. Modulating downhole cuttings via a pulsed jet for efficient drilling-tool development and field testing[J]. Journal of Natural Gas Science and Engineering, 2015, 27(9): 1287-1295.

[2] Y. Liu, J.P. Wei, T. Ren, et al. Experimental study of flow field structure of interrupted pulsed water jet and breakage of hard rock[J]. International Journal of Rock Mechanics and Mining Sciences, 2015, 78(9): 253-261.

[3] S. Dehkhoda, M. Hood. An experimental study of surface and sub-surface damage in pulsed water-jet breakage of rocks[J]. International Journal of Rock Mechanics and Mining Sciences, 2013, 63(10): 138-147.

[4] S. Dehkhoda, M. Hood. The internal failure of rock samples subjected to pulsed water jet impacts[J]. International Journal of Rock Mechanics and Mining Sciences, 2014, 66(2): 91-96.

[5] D. Li, Y. Kang, X.L. Ding, et al. Effects of area discontinuity at nozzle inlet on the characteristics of high speed self-excited oscillation pulsed waterjets[J]. Experimental Thermal and Fluid Science, 2016, 79(12): 254-265.

[6] J.H. Pei, Z.F. Liao, C.L. Tang. Experimental study on characteristics of self-excited oscillation pulsed water jet[J]. China Mechanical Engineering, 2009, 20(1): 60-63.

[7] F.L. Hew, V. Timchenko, J.A. Reizes, et al. Numerical evaluation of the effectiveness of micro pulsating water jets for cooling of microchips[C]. Proceedings of the ASME Micro/Nanoscale Heat and Mass Transfer International Conference, 2009: 625-633. 
[8] H. Orbanic, M. Junkar. Analysis of striation formation mechanism in abrasive water jet cutting[J]. Wear, 2008, 265: 821-830. 